\title{
Supervised Exercise Therapy for Intermittent Claudication Is Increasingly Endorsed by Dutch Vascular Surgeons
}

\author{
Citation for published version (APA): \\ Hageman, D., Lauret, G-J., Gommans, L. N. M., Koelemay, M. J. W., van Sambeek, M. R. H. M., \\ Scheltinga, M. R. M., \& Teijink, J. A. W. (2018). Supervised Exercise Therapy for Intermittent Claudication \\ Is Increasingly Endorsed by Dutch Vascular Surgeons. Annals of Vascular Surgery, 47, 149-156. \\ https://doi.org/10.1016/j.avsg.2017.08.022
}

Document status and date:

Published: 01/02/2018

DOI:

10.1016/j.avsg.2017.08.022

\section{Document Version:}

Publisher's PDF, also known as Version of record

\section{Document license:}

Taverne

Please check the document version of this publication:

- A submitted manuscript is the version of the article upon submission and before peer-review. There can be important differences between the submitted version and the official published version of record. People interested in the research are advised to contact the author for the final version of the publication, or visit the DOI to the publisher's website.

- The final author version and the galley proof are versions of the publication after peer review.

- The final published version features the final layout of the paper including the volume, issue and page numbers.

Link to publication

\footnotetext{
General rights rights.

- You may freely distribute the URL identifying the publication in the public portal. please follow below link for the End User Agreement:

www.umlib.nl/taverne-license

Take down policy

If you believe that this document breaches copyright please contact us at:

repository@maastrichtuniversity.nl

providing details and we will investigate your claim.
}

Copyright and moral rights for the publications made accessible in the public portal are retained by the authors and/or other copyright owners and it is a condition of accessing publications that users recognise and abide by the legal requirements associated with these

- Users may download and print one copy of any publication from the public portal for the purpose of private study or research.

- You may not further distribute the material or use it for any profit-making activity or commercial gain

If the publication is distributed under the terms of Article $25 \mathrm{fa}$ of the Dutch Copyright Act, indicated by the "Taverne" license above, 


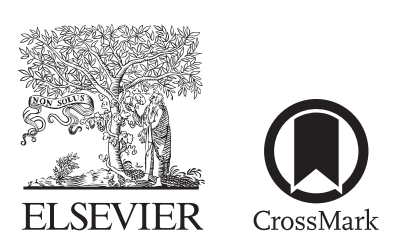

\title{
Supervised Exercise Therapy for Intermittent Claudication Is Increasingly Endorsed by Dutch Vascular Surgeons
}

\author{
David Hageman, ${ }^{1,2}$ Gert-Jan Lauret, ${ }^{1}$ Lindy N.M. Gommans, ${ }^{1}$ Mark J.W. Koelemay, ${ }^{3}$ \\ Marc R.H.M. van Sambeek, Marc R.M. Scheltinga, ${ }^{4}$ and Joep A.W. Teijink, ${ }^{1,2}$ Eindhoven, \\ Maastricht, Amsterdam, and Veldhoven, The Netherlands
}

\begin{abstract}
Background: Although supervised exercise therapy (SET) is generally accepted as an effective noninvasive treatment for intermittent claudication (IC), Dutch vascular surgeons were initially somewhat hesitant as reported by a 2011 questionnaire study. Later on, a nationwide multidisciplinary network for SET was introduced in the Netherlands. The aim of this questionnaire study was to determine possible trends in conceptions among Dutch vascular surgeons regarding the prescription of SET.

Methods: In the year of 2015, Dutch vascular surgeons, fellows, and senior residents were asked to complete a 26-item questionnaire including issues that were considered relevant for prescribing SET such as patient selection criteria and comorbidity. Outcome was compared to the 2011 survey.

Results: Data of 124 respondents ( $82 \%$ males; mean age 46 years; $64 \%$ response rate) were analyzed. SET referral rate of new IC patients was not different over time (2015: $81 \%$ vs. $2011: 75 \% ; P=0.295)$. However, respondents were more willing to prescribe SET in IC patients with chronic obstructive pulmonary disease $(2015: 86 \%$ vs. 2011: $69 \% ; P=0.002)$. Nevertheless, a smaller portion of respondents found that SET was also indicated for aortoiliac disease (2015: $63 \%$ vs. 2011 : $76 \% ; P=0.049)$. Insufficient health insurance coverage and/or personal financial resources were the most important presumed barriers preventing patients from initiating SET ( $80 \%$ of respondents). Moreover, $94 \%$ of respondents judged that SET should be fully reimbursed by all Dutch basic health insurances.

Conclusions: The concept of SET for IC is nowadays generally embraced by the vast majority of Dutch vascular surgeons. SET may have gained in popularity in IC patients with cardiopulmonary comorbidity. However, SET remains underutilized for aortoiliac disease. Reimbursement is considered crucial for a successful SET implementation.
\end{abstract}

J.A.W.T. is co-founder and chairman of ClaudicatioNet, a charitable foundation with no financial benefits for its founders or board members. D.H., G.-J.L., and L.N.M.G. are (former) PhD students for ClaudicatioNet. ClaudicatioNet is a nationwide network of specialized physiotherapists providing standardized supervised exercise therapy in the Netherlands(e-mail: info@claudicationet.nl).The remaining authors declare no conflicts of interest.

The authors received no specific grant from any funding agency in the public, commercial, or not-for-profit sectors.

${ }^{I}$ Department of Vascular Surgery, Catharina Hospital, Eindhoven, The Netherlands.

${ }^{2}$ Department of Epidemiology, CAPRHI School for Public Health and Primary Care, Faculty of Health, Medicine and Life Sciences, Maastricht University, Maastricht, The Netherlands.

\footnotetext{
${ }^{3}$ Department of Vascular Surgery, Academic Medical Center, Amsterdam, The Netherlands.

${ }^{4}$ Department of Vascular Surgery, Máxima Medical Center, Veldhoven, The Netherlands.

Correspondence to: Prof. Joep A.W. Teijink, MD, PhD, Vascular Surgeon, Department of Vascular Surgery, Catharina Hospital, Michelangelolaan 2, 5623 EJ Eindhoven, P.O. Box 1350, Eindhoven 5602 ZA, The Netherlands; E-mail: joep.teijink@catharinaziekenhuis.nl

Ann Vasc Surg 2018; 47: 149-156

https://doi.org/10.1016/j.avsg.2017.08.022

(c) 2017 Elsevier Inc. All rights reserved.

Manuscript received: June 12, 2017; manuscript accepted: August 1, 2017; published online: 9 September 2017
} 


\section{INTRODUCTION}

Contemporary international guidelines on the management of peripheral arterial disease (PAD) recommend supervised exercise therapy (SET) as first-line treatment for patients with intermittent claudication (IC). ${ }^{1-3}$ SET is equally effective but far more costeffective than endovascular revascularization regarding walking distance improvement. ${ }^{4,5}$ Moreover, SET is safe, improves quality of life, and may support national endeavors to reduce rates of obesity and diabetes. ${ }^{6-9}$ Nevertheless, implementation of SET is hampered by ongoing reimbursement issues and financial self-interest of vascular surgeons. ${ }^{10,11}$

A suboptimal global acceptance of SET is also due to a restricted volume of facilities providing SET. For instance, one study found that just $30 \%$ of the vascular surgeons worldwide have an option for SET referral. ${ }^{12}$ Since 2011 , ClaudicatioNet ensures immediate access for each patient with IC in the Netherlands. ${ }^{13,14}$ ClaudicatioNet is a nationwide multidisciplinary network of physiotherapists, vascular surgeons, and general practitioners (GPs). GPs and vascular surgeons are the initial caregivers to diagnose a patient with IC and thus, have the responsibility to assess associated cardiovascular risk factors and attributing lifestyle factors. Physiotherapists participating in ClaudicatioNet perform standardized SET and lifestyle interventions (e.g., smoking cessation, dietary advice, weight loss, increasing physical activity) and regularly assess medication adherence. Only trained physiotherapists who are qualified and undergo a yearly recertification are allowed to provide SET and lifestyle interventions in this organization.

Although SET is generally accepted as an effective noninvasive treatment, Dutch vascular surgeons were initially somewhat hesitant as reported by a 2011 questionnaire study. ${ }^{15}$ Nevertheless, $75 \%$ of new IC patients were prescribed SET at that point. However, vascular surgeons considered SET less useful in IC patients having cardiopulmonary comorbidity or with aortoiliac disease (as opposed to femoropopliteal disease). In recent years, the merits of SET are increasingly discussed in articles and at conferences. ${ }^{10,11,16,17}$ The aim of this questionnaire study was to determine possible trends in conceptions among Dutch vascular surgeons regarding the prescription of SET in IC patients.

\section{METHODS}

\section{Data Collection}

In the year of 2015, active members of the Dutch Society for Vascular Surgery including vascular surgeons, fellows, and senior residents were asked to complete a 26-item questionnaire regarding several aspects of SET as treatment option for IC (Appendix). Following society's endorsement, members were given the opportunity to complete a paper-based survey or a web-based e-mail survey. The questionnaire consisted of 3 open-ended questions, 6 multiple-choice questions, and 10 dichotomous (yes/no) questions. A portion of the questions $(n=8)$ were also included in the 2011 survey. ${ }^{15}$

The open-ended questions investigated the number of new IC patients per hospital per year, percentage of new IC patients who were referred for SET, and percentage of SET referrals to physiotherapists of ClaudicatioNet. The multiple-choice questions investigated SET as primary treatment in subgroups of IC patients, presumed barriers preventing patients from initiating SET, and presumed patient factors contributing to a decision whether or not to consider a primary vascular intervention. One dichotomous question considered reimbursement by Dutch basic health insurances.

\section{Data Management and Analysis}

Data were analyzed by 2 authors (D.H. and L.G.). Missing or ambiguous answers were excluded from analysis. Answers to questions regarding referral patterns of new IC patients were converted into estimated numbers or percentages. Means were calculated if ranges were provided. Consensus in case of disagreement was sought by discussion. Outcome of identical questions of the 2015 and 2011 survey $(n=8)$ was compared using standard testing. ${ }^{15}$ Summary statistics for continuous variables were reported as mean and standard deviation or as median and interquartile range (IQR) in case of a skewed distribution. An independent 2-sample $t$-test and nonparametric Mann-Whitney $\mathrm{U}$ and Kruskal-Wallis tests were used for comparison of continuous variables. Chi-squared and Fisher's exact tests were used to assess potential differences in categorical variables. A $P$-value $<0.05$ was considered statistically significant. All analyses were performed using SPSS 23 software (IBM Corporation, Armonk, NY).

\section{RESULTS}

\section{Study Population}

The Dutch Society for Vascular Surgery has 194 active members of which 124 (101 males, 82\%; age $46 \pm 9$ years) responded to the 2015 
Table I. Characteristics of Dutch vascular surgeons responding to questionnaires on SET

\begin{tabular}{|c|c|c|c|}
\hline & 2015 & 2011 & \\
\hline Demographic characteristic & $n=124(100 \%)$ & $n=91(100 \%)$ & $P$ value \\
\hline Gender & & & 0.481 \\
\hline Male & $102(82)$ & $78(86)$ & \\
\hline Female & $22(18)$ & $13(14)$ & \\
\hline Age (years) & & & 0.267 \\
\hline$\leq 40$ & $46(37)$ & $26(29)$ & \\
\hline $41-50$ & $43(35)$ & $43(47)$ & \\
\hline $51-60$ & $26(21)$ & $15(17)$ & \\
\hline$>60$ & $9(7)$ & $7(8)$ & \\
\hline Professional career & & & 0.114 \\
\hline Vascular surgeon & $104(84)$ & $83(91)$ & \\
\hline Fellow or senior resident & $20(16)$ & $8(9)$ & \\
\hline Working experience as vascular surgeon (years) & & & 0.555 \\
\hline$\leq 5$ & $29(28)$ & $22(27)$ & \\
\hline $6-15$ & $40(38)$ & $38(46)$ & \\
\hline$>15$ & $35(34)$ & $23(28)$ & \\
\hline Hospital setting & & & 0.965 \\
\hline Academic & $20(16)$ & $15(16)$ & \\
\hline Nonacademic & $104(84)$ & $76(84)$ & \\
\hline Working region & & & 0.655 \\
\hline North of Netherlands & $16(13)$ & $8(9)$ & \\
\hline East of Netherlands & $26(21)$ & $21(23)$ & \\
\hline West of Netherlands & $59(48)$ & $41(45)$ & \\
\hline South of Netherlands & $23(18)$ & $21(23)$ & \\
\hline
\end{tabular}

questionnaire (2015: 64\% response rate versus 2011: 51\% response rate). ${ }^{15}$ Demographic characteristics are shown in Table I. No differences between the 2015 and 2011 cohort were found.

\section{Referral Patterns of New IC Patients}

In the year of 2015, the number of new IC patients per hospital per year was estimated at 347 (median 300, IQR 200-400). Of these patients, an estimated $81 \%$ (median 80, IQR 75-95) was referred for SET compared to $75 \%$ (median 80, IQR 66-95) in 2011 $(P=0.295) .{ }^{15}$ SET referral rate was highest in the southern part of the Netherlands $(87 \%$, median 100, IQR 94-100) and lowest in the eastern part (69\%, median 75, IQR 50-98; $P=0.003)$. Familiarity with ClaudicatioNet was $100 \%$. However, $73 \%$ of the respondents referred to physiotherapists of ClaudicatioNet, whereas $27 \%$ used an independent local network of physiotherapists. Regional differences were not observed. Interestingly, highly experienced vascular surgeons more often used an independent local network of physiotherapists compared to less experienced vascular surgeons (>15 years of working experience: $47 \%$ versus $\leq 15$ years of working experience: $20 \%$; $P=0.028)$.

\section{SET in Comorbid IC Patients}

Table II shows trends in attitude of vascular surgeons towards SET as primary treatment in subgroups of IC patients. Compared to 2011, vascular surgeons in 2015 were more willing to prescribe SET in IC patients with chronic obstructive pulmonary disease (COPD; 2015: 86\% vs. 2011: 69\%; $P=0.002)$. Moreover, they judged that SET was also indicated in the vast majority of IC patients with coronary artery disease (CAD), congestive heart failure $(\mathrm{CHF})$, diabetes mellitus, older individuals with severe limitations in activities of daily living, and younger individuals with severe disability in employment. Nevertheless, a smaller portion of vascular surgeons found that SET was also indicated for aortoiliac disease (2015: 63\% vs. 2011: 76\%; $P=0.049$ ). Interestingly, academic respondents considered SET less useful in patients with IC due to aortoiliac stenosis or occlusion compared to nonacademic respondents (academic: $40 \%$ versus nonacademic: $67 \% ; P=0.041)$.

\section{Patient Factors Determining Referral for SET}

Patient factors determining referral for SET in IC patients as perceived by Dutch vascular surgeons are 
Table II. Willingness of Dutch vascular surgeons to prescribe SET as primary treatment in comorbid IC patients

\begin{tabular}{|c|c|c|c|c|c|}
\hline \multirow[b]{2}{*}{ Subgroup of IC patients } & \multicolumn{2}{|c|}{2015} & \multicolumn{2}{|c|}{2011} & \multirow[b]{2}{*}{$P$ value } \\
\hline & $\%$ & $n$ & $\%$ & $n$ & \\
\hline Patients with $\mathrm{DM}^{\mathrm{a}}$ & 98 & $121 / 124$ & - & - & - \\
\hline Patients with $\mathrm{CAD}^{\mathrm{a}}$ & 90 & $111 / 124$ & - & - & - \\
\hline Patients with COPD & 86 & $107 / 124$ & 69 & $60 / 87$ & 0.002 \\
\hline $\begin{array}{l}\text { Younger patients with severe disability in } \\
\text { employment }^{\mathrm{a}}\end{array}$ & 80 & $99 / 124$ & - & - & - \\
\hline Patients with CHF & 75 & $93 / 124$ & 71 & $60 / 84$ & 0.567 \\
\hline Older patients with severe limitations in ADLs ${ }^{a}$ & 73 & $91 / 124$ & - & - & - \\
\hline Patients with IC due to aortoiliac stenosis/occlusion & 63 & $78 / 124$ & 76 & $63 / 83$ & 0.049 \\
\hline
\end{tabular}

IC, intermittent claudication; DM, diabetes mellitus; CAD, coronary artery disease; COPD, chronic obstructive pulmonary disease; CHF, congestive heart failure; ADLs, activities of daily living.

${ }^{\text {a }}$ Question not included in 2011 questionnaire. ${ }^{15}$

depicted in Figure 1. Walking distance, age, and ankle-brachial index were considered important parameters. In addition, respondents also reported additional factors including patient's needs, wishes and preferences $(n=6)$, limitations in activities of daily living $(n=6)$, cardiopulmonary comorbidity $(n=6)$, general disability $(n=5)$, anatomical location of the stenosis/occlusion $(n=4)$, musculoskeletal comorbidity $(n=4)$, patient motivation $(n=4)$, therapy compliance $(n=3)$, limitations in employment $(n=2)$, critical limb ischemia $(n=2)$, general physical condition $(n=2)$, and reimbursement of SET $(n=2)$.

\section{Barriers Precluding Universal Adherence to SET}

Four of 5 respondents $(80 \%)$ considered insufficient health insurance coverage and/or personal financial resources as important barriers preventing patients from initiating SET. Moreover, 59\% reported lack of patient motivation whereas just $2 \%$ had negative associations with SET. A total of $94 \%$ agreed with the notion that SET should be fully reimbursed by all Dutch basic health insurances.

\section{SET Progress Reports in Daily Practice}

A total of $97 \%$ of the respondents claimed to have received written feedback from physiotherapists on progress in treatment goals including changes in walking distance, quality of life, and lifestyle as well as perceived reasons for failure (Table III). Moreover, $90 \%$ indicated that physiotherapist's feedback contributed to a decision whether or not to discuss a vascular intervention. Interestingly, highly experienced vascular surgeons indicated that physiotherapist's feedback less often

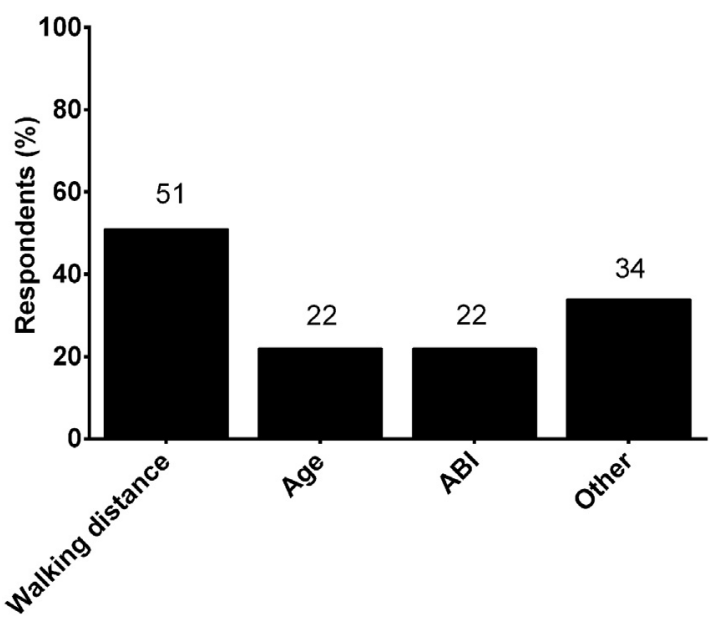

Fig. 1. Patient factors determining referral for SET as judged by Dutch vascular surgeons. ABI, ankle-brachial index.

contributed to a decision compared to less experienced vascular surgeons ( $>15$ years of working experience: $79 \%$ versus $\leq 15$ years of working experience: $96 \% ; P=0.011)$.

\section{Patient Factors Determining a Primary Vascular Intervention}

Patient factors contributing to a decision to consider a primary vascular intervention (angioplasty or bypass surgery) in IC patients as perceived by Dutch vascular surgeons are depicted in Figure 2. Disability in employment, limitations in activities of daily living, and the anatomical location of the stenosis/ occlusion were considered the most important parameters. In addition, respondents also reported additional factors including symptoms and 
Table III. SET progress reports in daily practice

\begin{tabular}{|c|c|c|c|c|c|}
\hline \multirow[b]{2}{*}{ Aspect of feedback } & \multicolumn{2}{|c|}{2015} & \multicolumn{2}{|c|}{2011} & \multirow[b]{2}{*}{$P$ value } \\
\hline & $\%$ & $n$ & $\%$ & $n$ & \\
\hline Received written feedback from physiotherapists & 97 & $120 / 124$ & 88 & $52 / 59$ & 0.040 \\
\hline $\begin{array}{l}\text { Physiotherapist's feedback contributed to decision to } \\
\text { discuss vascular intervention }\end{array}$ & 90 & $112 / 124$ & 87 & $77 / 89$ & 0.386 \\
\hline
\end{tabular}

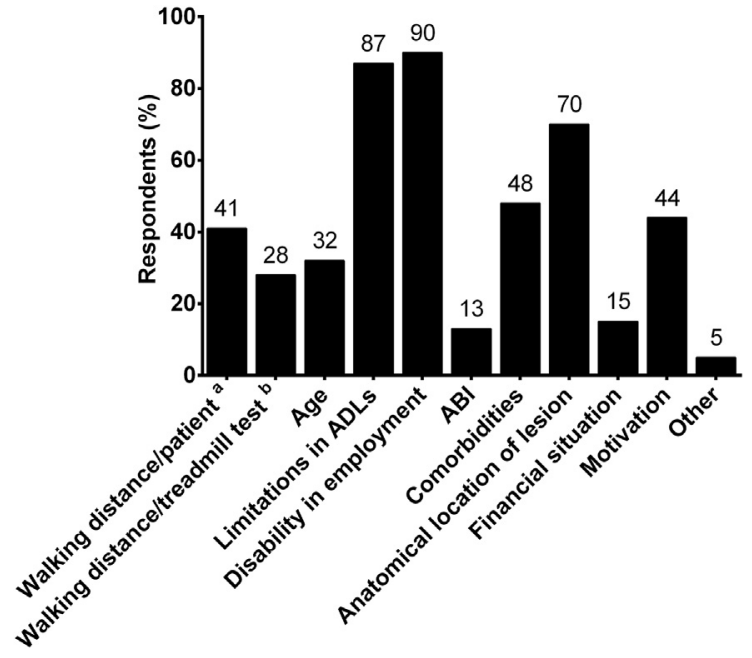

Fig. 2. Patient factors determining a primary vascular intervention as judged by Dutch vascular surgeons. ${ }^{\mathrm{a}}$ Walking distance indicated by patient; ${ }^{\mathrm{b}}$ walking distance measured by treadmill test; ADLs, activities of daily living; ABI, ankle-brachial index.

complaints $(n=4)$ and successful smoking cessation $(n=2)$.

\section{DISCUSSION}

This questionnaire study aimed to determine possible trends in conceptions among Dutch vascular surgeons regarding the prescription of SET in IC patients. The results of our study show that Dutch vascular surgeons have a persistent positive attitude toward SET as first-line treatment option for IC. SET referral rate in general did not differ since 2011 as in the year 2015, 4 of 5 new Dutch IC patients received a SET-first advice. However, SET gained popularity in IC patients with cardiopulmonary comorbidity. This increased referral rate is possibly explained by a stronger belief that exercise is not only effective in improving walking ability but also stimulates general cardiopulmonary fitness and quality of life in this subgroup of IC patients. This notion is supported by ample evidence indicating that exercise rehabilitation is essentially beneficial for patients with symptomatic COPD, CHF, and CAD. ${ }^{18-20}$ Therefore, aerobic training should be part of all cardiopulmonary rehabilitation programs as recommended in the guidelines of these individual diseases. ${ }^{21-23}$ In line with these guidelines, we strongly feel that a first-line SET treatment strategy is beneficial in all IC patients including those suffering from cardiopulmonary comorbidity.

Apart from a positive influence on cardiopulmonary performance, SET also offers a unique opportunity to unveil the primary problem underlying restrictions in walking function and trainability in IC patients. In the Dutch situation, physiotherapists of Claudicationet will standardly inform the vascular surgeon and GP on progress in treatment goals as well as perceived reasons for failure. The intense contact between physiotherapist and patient allows for the identification of conditions other than IC precluding proper walking such as COPD, CHF, osteoarthritis, spinal stenosis, or balance disorders. If these comorbidities are considered more limiting than the atherosclerotic lesion, such a patient will be discussed with the referring physician possibly preventing potentially futile vascular interventions for nonlimiting obstructions. As found in the present study, the percentage of respondents claiming to have received written feedback from physiotherapists is close to optimal (97\%). Moreover, 90\% indicated that physiotherapist's feedback contributed to a decision whether or not to discuss a vascular intervention. These findings indicate that stimulation of cohesion and collaboration between various healthcare professionals in a multidisciplinary network (physiotherapists, vascular surgeons, and GPs) may result in optimized care for patients with IC.

One of the somewhat surprising findings of the present study is the continuing underutilization of SET for aortoiliac disease. There are several potential explanations for a limited popularity of SET under these circumstances. First, surgeons have 
considerable experience with percutaneous transluminal angioplasty (PTA) and stent revascularization in the aortoiliac segment, and the results are more predictable and durable than in the femoropopliteal segment. $^{24-28}$ Second, ambiguities in outdated guidelines might have caused lack of appreciation of SET for IC caused by aortoiliac lesions. ${ }^{29-31}$ However, recently updated guidelines suggest a SET-first approach for all types of lesions. ${ }^{1-3,32}$ Results of the CLEVER study demonstrated that SET and stent revascularization provided a similar improvement in functional status and quality of life in the long term. ${ }^{4}$ Currently, the results of the SUPER study are awaited. ${ }^{33}$ This multicenter randomized controlled trial in over 200 patients investigates whether SET and deferred PTA (in case of SET failure) or immediate PTA is the optimal treatment strategy for IC due to an iliac artery obstruction. Considering the available evidence at this point however, there is no reason to withhold SET from IC patients with aortoiliac disease. Also, from a practical point of view, initiation of SET should not be delayed by extensive imaging of disease location, since there is no evidence that level of obstruction has any consequences for the initiation of primary conservative treatment for IC.

There is a wide variation regarding the availability of SET programs in Europe. Availability rates of about $10 \%$ were identified in Greece and Spain. ${ }^{12}$ Surveys on the availability of SET programs among British surgeons showed that no significant progress was made over the last 15 years. ${ }^{12,34,35}$ Conversely, a nationwide $100 \%$ coverage is attained in the Netherlands as guaranteed by the efforts of ClaudicatioNet. ${ }^{12-14}$ Some consider the substantial investment to achieve nationwide implementation of SET programs as a problem. ${ }^{36}$ However, initial investments to increase the availability of SET may be cost-saving when a SET-first treatment strategy (stepped care model) is followed. ${ }^{37}$ This should be a motivation for other European countries to implement such a network. The ClaudicatioNet concept could serve as a blueprint for the implementation of structured SET programs in all European countries.

Despite full availability of SET programs in the Netherlands, several barriers still seriously impede total implementation of structured SET programs. The present study suggests that increased enthusiasm for interventional procedures and a lack of appreciation of SET in certain IC subgroups, such as patients with aortoiliac lesions, may play a role in the underutilization. However, lack of health insurance coverage and/or personal financial resources was found to be the most important presumed barriers preventing patients from initiating SET (80\% of respondents). Moreover, the vast majority (94\% of respondents) judged that SET should be fully reimbursed. These findings once again demonstrate that reimbursement is crucial for a successful SET implementation. Funding of SET, as available from January 1, 2017 in the Netherlands, should therefore be made available in all European countries.

\section{Limitations}

This study has some limitations. First, response and participation bias might have influenced the results, most likely in favor of a positive attitude toward SET. Second, reported referral rates are estimates and not calculated numbers. Therefore, data should be interpreted with caution. Finally, response rates are relatively low, and it is uncertain how many of the participants completed both surveys. However, both studies are representative as a nationwide survey, whereas no differences in demographic characteristics were found.

\section{CONCLUSION}

The concept of SET for IC is nowadays generally embraced by the vast majority of Dutch vascular surgeons. The present study revealed interesting trends regarding the prescription of SET in subgroups of IC patients. SET may have gained in popularity among Dutch vascular surgeons as first-line treatment in IC patients with cardiopulmonary comorbidity. However, SET remains underutilized in patients with IC due to aortoiliac disease. Reimbursement is considered crucial for a successful SET implementation.

The authors would like to thank Danielle van Dalen, Regine van Grinsven, Loes Hellegers, Yvonne Spierings-Peeters, Eva Troe, and Nicole Verhofstad for their contributions to the data collection.

\section{SUPPLEMENTARY DATA}

Supplementary data related to this article can be found at https://doi.org/10.1016/j.avsg.2017.08. 022 .

\section{REFERENCES}

1. Layden J, Michaels J, Bermingham S, et al. Diagnosis and management of lower limb peripheral arterial disease: summary of NICE guidance. BMJ 2012;345:e4947. 
2. Conte MS, Pomposelli FB, Clair DG, et al. Society for Vascular Surgery practice guidelines for atherosclerotic occlusive disease of the lower extremities: management of asymptomatic disease and claudication. J Vasc Surg 2015;61 (3 Suppl):2S-41S.

3. Gerhard-Herman MD, Gornik HL, Barrett C, et al. 2016 AHA/ACC Guideline on the Management of Patients With Lower Extremity Peripheral Artery Disease: A Report of the American College of Cardiology/American Heart Association Task Force on Clinical Practice Guidelines. Circulation 2017;135:e726-79.

4. Murphy TP, Cutlip DE, Regensteiner JG, et al. Supervised exercise, stent revascularization, or medical therapy for claudication due to aortoiliac peripheral artery disease: the CLEVER study. J Am Coll Cardiol 2015;65:999-1009.

5. Mazari FA, Khan JA, Carradice D, et al. Economic analysis of a randomized trial of percutaneous angioplasty, supervised exercise or combined treatment for intermittent claudication due to femoropopliteal arterial disease. Br J Surg 2013;100: $1172-9$.

6. Gommans LN, Fokkenrood HJ, van Dalen HC, et al. Safety of supervised exercise therapy in patients with intermittent claudication. J Vasc Surg 2015;61:512-518.e2.

7. Nicolai SP, Teijink JA, Prins MH. Multicenter randomized clinical trial of supervised exercise therapy with or without feedback versus walking advice for intermittent claudication. J Vasc Surg 2010;52:348-55.

8. Shaw K, Gennat H, O'Rourke P, et al. Exercise for overweight or obesity. Cochrane Database Syst Rev 2006;CD003817.

9. Orozco LJ, Buchleitner AM, Gimenez-Perez G, et al. Exercise or exercise and diet for preventing type 2 diabetes mellitus. Cochrane Database Syst Rev 2008; CD003054.

10. Popplewell MA, Bradbury AW. Why do health systems not fund supervised exercise programmes for intermittent claudication? Eur J Vasc Endovasc Surg 2014;48:608-10.

11. Gommans LN, Teijink JA. Attitudes to supervised exercise therapy. Br J Surg 2015;102:1153-5.

12. Makris GC, Lattimer CR, Lavida A, et al. Availability of supervised exercise programs and the role of structured home-based exercise in peripheral arterial disease. Eur J Vasc Endovasc Surg 2012;44:569-75. discussion 76.

13. Lauret GJ, Gijsbers HJ, Hendriks EJ, et al. The ClaudicatioNet concept: design of a national integrated care network providing active and healthy aging for patients with intermittent claudication. Vasc Health Risk Manag 2012;8: 495-503.

14. Fokkenrood HJ, Lauret GJ, Scheltinga MR, et al. Multidisciplinary treatment for peripheral arterial occlusive disease and the role of eHealth and mHealth. J Multidiscip Healthc $2012 ; 5: 257-63$.

15. Lauret GJ, van Dalen HC, Hendriks HJ, et al. When is supervised exercise therapy considered useful in peripheral arterial occlusive disease? A nationwide survey among vascular surgeons. Eur J Vasc Endovasc Surg 2012;43: 308-12.

16. Fakhry F, Spronk S, van der Laan L, et al. Endovascular revascularization and supervised exercise for peripheral artery disease and intermittent claudication: a randomized clinical trial. JAMA 2015;314:1936-44.

17. Beard J. Exercise therapy for claudicants - the guidance from NICE and other healthcare regulators is being ignored. In: Shearman CP ed. Peripheral Arterial Challenges.
London, England, UK: Charing Cross International Symposium, 2016.

18. McCarthy B, Casey D, Devane D, et al. Pulmonary rehabilitation for chronic obstructive pulmonary disease. Cochrane Database Syst Rev 2015;CD003793.

19. Taylor RS, Sagar VA, Davies EJ, et al. Exercise-based rehabilitation for heart failure. Cochrane Database Syst Rev 2014; CD003331.

20. Heran BS, Chen JM, Ebrahim S, et al. Exercise-based cardiac rehabilitation for coronary heart disease. Cochrane Database Syst Rev 2011;CD001800.

21. Smith SC, Benjamin EJ, Bonow RO, et al. AHA/ACCF secondary prevention and risk reduction therapy for patients with coronary and other atherosclerotic vascular disease: 2011 update: a guideline from the American Heart Association and American College of Cardiology Foundation. Circulation 2011;124:2458-73.

22. Montalescot G, Sechtem U, Achenbach S, et al. 2013 ESC guidelines on the management of stable coronary artery disease: the Task Force on the management of stable coronary artery disease of the European Society of Cardiology. Eur Heart J 2013;34:2949-3003.

23. Yancy CW, Jessup M, Bozkurt B, et al. 2013 ACCF/AHA guideline for the management of heart failure: a report of the American College of Cardiology Foundation/American Heart Association Task Force on Practice Guidelines. J Am Coll Cardiol 2013;62:e147-239.

24. Sapoval MR, Long AL, Raynaud AC, et al. Femoropopliteal stent placement: long-term results. Radiology 1992;184: 833-9.

25. Vroegindeweij D, Vos LD, Tielbeek AV, et al. Balloon angioplasty combined with primary stenting versus balloon angioplasty alone in femoropopliteal obstructions: a comparative randomized study. Cardiovasc Intervent Radiol 1997;20:420-5.

26. Murphy TP, Ariaratnam NS, Carney WI Jr, et al. Aortoiliac insufficiency: long-term experience with stent placement for treatment. Radiology 2004;231:243-9.

27. Schlager O, Dick P, Sabeti S, et al. Long-segment SFA stenting-the dark sides: in-stent restenosis, clinical deterioration, and stent fractures. J Endovasc Ther 2005; 12:676-84.

28. Laird JR. Limitations of percutaneous transluminal angioplasty and stenting for the treatment of disease of the superficial femoral and popliteal arteries. J Endovasc Ther 2006;13(Suppl 2):II30-40.

29. Vahl AC, Mali W, van Overhagen H, et al. Guideline ‘Diagnosis and treatment of arterial disease of the lower extremity'. [Richtlijn 'Diagnostiek en behandeling van arterieel vaatlijden van de onderste extremiteit'] (Dutch). Dutch Society for Surgery 2005. Available at: http://heelkunde.nl/ sites/heelkunde.nl/files/richtlijnen-definitief/Diagnostiek-enbehandeling-van-arterieel-vaatlijden-van-de-onderste-extrem iteit.pdf.

30. Hirsch AT, Haskal ZJ, Hertzer NR, et al. ACC/AHA Guidelines for the Management of Patients with Peripheral Arterial Disease (lower extremity, renal, mesenteric, and abdominal aortic): a collaborative report from the American Associations for Vascular Surgery/Society for Vascular Surgery, Society for Cardiovascular Angiography and Interventions, Society for Vascular Medicine and Biology, Society of Interventional Radiology. J Vasc Interv Radiol 2006;17: 1383-98.

31. Norgren L, Hiatt WR, Dormandy JA, et al. Inter-Society Consensus for the Management of Peripheral Arterial Disease (TASC II). J Vasc Surg 2007;45(Suppl S):S5-67. 
32. Vahl AC, Teijink JA, Hendriks JM, et al. Concept guideline 'Diagnosis and Treatment of Patients with Peripheral Arterial Disease of the Lower Extremity'. [Conceptrichtlijn 'Diagnostiek en Behandeling van Patiënten met Perifeer Arterieel Vaatlijden van de Onderste Extremiteit'] (Dutch). Dutch Society for Surgery 2015. Available at: http:// heelkunde.nl/sites/heelkunde.nl/files/Bijlage-1-Conceptrich tlijn-Diagnostiek-en-Behandeling-van-Patienten-met-PerifeerArterieel-Vaatlijden.pdf.

33. Frans FA, Bipat S, Reekers JA, et al. SUPERvised exercise therapy or immediate PTA for intermittent claudication in patients with an iliac artery obstruction-a multicentre randomised controlled trial; SUPER study design and rationale. Eur J Vasc Endovasc Surg 2012;43:466-71.
34. Cassar K, Belch JJF, Brittenden J. Are national cardiac guidelines being applied by vascular surgeons? Eur J Vasc Endovasc Surg 2003;26:623-8.

35. Shalhoub J, Hamish M, Davies AH. Supervised exercise for intermittent claudication - an under-utilised tool. Ann R Coll Surg Engl 2009;91:473-6.

36. Bermingham SL, Sparrow K, Mullis R, et al. The costeffectiveness of supervised exercise for the treatment of intermittent claudication. Eur J Vasc Endovasc Surg 2013;46:707-14.

37. Fokkenrood HJ, Scheltinga MR, Koelemay MJ, et al. Significant savings with a stepped care model for treatment of patients with intermittent claudication. Eur J Vasc Endovasc Surg 2014;48:423-9. 